\title{
De que violência fala a mídia?
}

What kind of violence does the media talks about?

\section{Marlene Branca Sólio}

Jornalista; doutora em Comunicação, pelo Programa de Pós-Graduação da Pontifícia Universidade Católica do Rio Grande do Sul PPG/PUC-RS; professora e pesquisadora no Centro de Ciências da Comunicação da Universidade de Caxias do Sul - UCS; líder de grupo - Mídia, discurso, imagens e práticas sociais.

E-mail: brancasolio@gmail.com

\section{Resumo}

Este artigo nasceu de pesquisa que analisa o tratamento dado pela mídia impressa a questões da violência urbana, com ênfase em homicídios, abusos sexuais e sequestros. A pesquisa inicial, desenvolvida pela Mitra Diocesana de Caxias do Sul, fez uma análise essencialmente quantitativa nos jornais Pioneiro e Zero Hora, com tabulação de 5.370 registros em Zero Hora e 2.067 no Pioneiro, no período de 1ํ de janeiro de 1994 a 30 de novembro de 2004. Esse foi o impulso para uma segunda etapa no trabalho, que contemplou os jornais Pioneiro, Correio do Povo, Zero Hora e Folha de S. Paulo a partir de reflexão apoiada na dialética histórico-estrutural (DHE) e com a análise do discurso (AD). No presente trabalho, buscou-se apontar situações em que o discurso evidencia um estereótipo de violência que "camufla" o que se considera a real violência impingida à sociedade.

Palavras-chave: Jornalismo. Notícia. Violência.

\begin{abstract}
This article stems from the research that examines the treatment given by the press to issues of urban violence, focusing on homicide, sexual abuse and kidnapping, without ignoring other manifestations of the phenomenon. Initial survey, developed by Mitra Diocesan from Caxias do Sul, made analysis essentially quantitative, in newspapers Pioneiro and Zero Hora, with tabulation of 5370 records in Zero Hora and 2067 in Pioneer, from January 1, 1994 to November 30, 2004. This was the start for a second stage in the work, which included the newspapers Pioneiro, Correio do Povo, Zero Hora and Folha de S. Paulo from reflection supported by the Dialectic and Historical-Structural and with Discourse Analysis. At this paper, we point out situations where the speech shows a stereotype of violence that "camouflages" what we consider the real violence foisted on society.
\end{abstract}

Keywords: Journalism. News. Violence. 


\section{Sobre o mundo que cerca as pessoas em geral}

A sociedade contemporânea registra inegável avanço tecnológico. Esta premissa leva a uma reflexão sobre que tipo de relação se estabelece entre esses dois atores. É comum a produção intelectual presa a questões de causa e efeito. Assim, entende-se que uma análise deva ser dialética, precisando envolver outras instâncias. O pontochave de discussão passa pela compreensão, por exemplo, do tipo de Estado, do modelo de sociedade e do uso que ela fará dessa tecnologia para articulações sociais, políticas e econômicas.

Em um Estado neoliberal ${ }^{1}$, onde quem detém o poder de gerenciamento, manipulação e barganha é a iniciativa privada, a tecnologia informacional assume papel relevante na determinação de processos/relações sociais em sintonia com a ideologia das elites dominantes. Esse domínio se atualiza de diferentes maneiras, e neste trabalho o recorte de análise é o jornalístico, pois alcança profunda repercussão na comunidade, na medida em que ela normalmente o legitima como supostamente verdadeiro, objetivo, imparcial e neutro (TraQUINA, 2001), posto que "acima do bem e do mal", lugar onde estaria, também, a ciência.

Traquina falou no paradigma construtivista, segundo o qual,

[...] embora sendo índice do "real", as notícias registram as formas literárias e as narrativas utilizadas para enquadrar acontecimentos. A pirâmide invertida, a ênfase dada às respostas, às perguntas aparentemente simples Quem? O quê? Onde? Quando? -, a necessidade de selecionar, excluir, acentuar diferentes aspectos do acontecimento [...] são alguns exemplos de como a notícia, dando vida ao acontecimento, constrói o acontecimento e constrói a realidade (2001: 87).

Traquina lembrou que "os membros da comunidade jornalística exercem um grau de autonomia" (2001: 86), contestando a visão de jornalistas como meros observadores passivos. "Ao contrário, são de fato participantes na construção da realidade" (p. 86). Ao recortar a realidade e

\footnotetext{
${ }^{1} \mathrm{O}$ neoliberalismo sustenta a apoteose da propriedade privada e da livre competição. Institui em princípio-chave a liberdade de empreendimento e de escolha individual. Acredita que o interesse próprio constitui um móvel dominante dos agentes sociais (egoísmo ético). Propõe a operação da "mão invisível" de Adam Smith e, em consequência, dispensa qualquer interferência do Estado na economia. Pretende "resgatar a naturalidade" das leis de mercado, com a plena vigência dos sistema de preços, e abre mão da rede de segurança social aos desvalidos. Por fim, advoga a lei de sobrevivência dos mais aptos, ao gosto de Herbert Spencer, numa furiosa exclusão social (SRours, Robert. Poder, cultura e ética nas organizações. Rio de Janeiro: Campus, 1998. p. 95).
}

oferecê-la ao público como verdade, as mudanças efetuadas durante a captação, no processo de produção e na difusão do fato, terão forte poder sobre a forma de percepção do público.

Entende-se, a partir disso, a possibilidade de o discurso jornalístico afetar o autoconceito do público sistematicamente. Acredita-se que a "construção de imagem e da realidade social" está diretamente relacionada ao fato de o sujeito verse no Outro de modo mais intenso do que vê a si. E, quando não encontra um Outro consciente de suas limitações e poderes, acaba por confundir as noções básicas de convivência social, como ética nas relações (BAKTHIN, 1988)2.

A facilidade de manipulação das consciências sociais, encontrada pela mídia, não pode, entretanto, ser analisada simplesmente pela teoria behaviorista. É preciso ir além. Parece que recorrer a Morin (2005) enriqueceria a reflexão. Pode-se lembrar o princípio do "anel recursivo", em que produtos e efeitos são eles próprios produtores e causadores daquilo que os produz. Assim, talvez se possa perceber na mídia, por meio de um discurso insistentemente repetido, a competência para tornar crescentemente difusa a capacidade perceptivo-cognitiva dos sujeitos. É possível, também, pensar a partir da outra ponta do circuito: tecnologia, mídia e discurso midiático são resultantes de um processo de simbolização gerado pelos sujeitos que, assim, tanto podem ser vistos como produto de uma sociedade que os sufoca e aliena quanto produtores de uma sociedade alienante.

\section{Sobre o método do trabalho}

Considera-se importante a busca de estudos inter e transdisciplinares para as questões enfocadas, geralmente, como específicas da comunicação, o que denota reducionismo na análise. Entende-se que o objeto da comunicação perpassa as mais diversas áreas do conhecimento. $\mathrm{Na}$ medida em que são analisados fenômenos comunicacionais de grupo, não é possível desvincular observa-

\footnotetext{
2 Para Bakthin, "a verdadeira substância da língua [...] não é constituída de um sistema abstrato de formas linguísticas [...] mas pelo fenômeno social da interação verbal, realizada através da enunciação e das enunciações". Ainda segundo este autor, o "outro" desempenha um papel fundamental. O sujeito é inconcebível fora das relações. "Não tomo consciência de mim mesmo, a não ser através dos outros, é deles que recebo as palavras, as formas, a tonalidade que formam a primeira imagem de mim mesmo. Só me torno consciente de mim mesmo revelando-me para o outro, através do outro e com a ajuda do outro" (BAKTHIN, Mikhail. Marxismo e filosofia da linguagem: problemas fundamentais do método sociológico na ciência da linguagem. 9. ed. São Paulo: Hucitec, 1988).
} 
ções da Sociologia, por exemplo. Quando se afirma que esses fenômenos acontecem num tempo e num espaço, fica-se de mãos dadas com a História e com a Antropologia. $\mathrm{E}$, quando se trabalha com um sujeito, não se pode descartar a Filosofia e a Psicanálise.

Assim, por meio da dialética histórico-estrutural (DHE), mas sem descartar contribuições da complexidade de Morin, por exemplo, que incita o pesquisador a não limitar a perspectiva do olhar, pode-se tentar compreender/explicar a sociedade e as relações sociais como um fenômeno estrutural, dinâmico e em permanente transformação - dialógico, portanto. É que o sujeito, em sua complexidade, procura por/ estabelece pontos de fuga na sociedade da informação/ tecnologia que, paradoxalmente, o mantém sob permanente controle/vigilância. Entende-se que, ao tentar compreender essa relação, seja possível perceber as condições objetivas e subjetivas estabelecidas entre o sujeito social e os mecanismos da sociedade/Estado. Estes pretendem amordaçálo e/ou mantê-lo excluído de um cenário de bem-estar, diluindo/esmaecendo conceitos como os de classe social, o que dificulta a localização das fontes de onde emana o poder e o desenho da ordem social vigente. Percebe-se, ainda, que o sujeito dispõe de um potencial cognitivo-perceptivo que antecede sua inserção no mundo que o estrutura como linguagem. Daí a possibilidade da tensão permanente, do conflito como resposta, e não como anomia.

Com a DHE, pode-se conjugar o estruturalismo e o marxismo, que teve como expoentes, na escola francesa da análise do discurso, até o fim dos anos 1960, pensadores como Althusser e Foucault. A partir dos anos 1970, principalmente, sobressaíram-se, também, estudos focados na Psicanálise (Freud e Lacan), evidenciando aspectos do inconsciente e da subjetividade do sujeito estruturado como linguagem. É importante destacar que, a partir desse período, estudos ligados ao marxismo foram banidos do palco da intelectualidade, disposta a "desfazer-se da criança juntamente com a água do banho".

Por meio da dialética, a DHE busca compreender os princípios dinâmicos, de movimento; com o estruturalismo, olha para o que está posto. Por intermédio desse paradigma, contemplam-se, então, os aspectos objetivos e os subjetivos da realidade, ao serem consideradas as dimensões histórica e social, numa visão de história dinâmica e complexa em que conflitos são transformadores. A intenção da DHE não é dar conta de tudo, mas focar-se no movimento.

Ao se buscar amparo nos paradigmas apontados, pretende-se cotejar as reflexões com a proliferação de um discurso de sustentação autorreferencial, ou seja, da própria mídia, que contribui para a fixação de um discurso ideológico dos meios de comunicação e, por meio dele, de um modelo de Estado e de uma elite dominante. Até pouco tempo, proclamava-se, com ênfase, o papel fundamental da mídia nas democracias. Mas a instituição, pelos sujeitos sociais, de pontos de fuga em relação ao processo informacional, abalou a credibilidade dos veículos de comunicação, não a ponto de promover uma transformação radical no sistema, mas a ponto de mostrar novos caminhos possíveis para a relação do sujeito social com o trinômio "sistema informacional/elites dominantes/Estado". E é justamente essa perspectiva que se pretende abordar. Parece importante evidenciar que os estudos de recepção são basais para a análise de questões fundantes da comunicação. Mas é importante, também, destacar o fato de que, principalmente a partir da tecnologização da sociedade, esse mesmo receptor é, também e concomitantemente, produtor dessa mesma sociedade. E a prova mais elementar desse fato está, por exemplo, na crescente participação de cidadãos comuns (receptores) na produção de conteúdos/pautas. Precisa-se frisar, porém, que esse cenário se desenha, ainda, como tendência/possibilidade, e que, em muitas situações, é usado pelas próprias indústrias de produção cultural como estratégia de convencimento de uma pseudodemocracia midiática.

\section{Sobre a técnica metodológica}

A técnica metodológica empregada no trabalho aqui apresentado foi a análise do discurso (AD), com base em Althusser, Foucault e Pêcheux. E, como foi enfatizado anteriormente, a reflexão sobre o papel da mídia na arquitetura das relações sociais tende a contemplar registros unilaterais, sem considerar a relação/contaminação entre sociedade centrada em sistemas de informação e tecnologia/ elites dominantes/Estado/sujeitos sociais. Assim, parece relevante um estudo que traga para um primeiro plano o papel dos sujeitos sociais e as relações desses sujeitos como geradoras de um novo espaço/tempo social diante do pseudodeterminismo tecnológico, e mesmo econômico, insinuado pela mídia.

O recorte temporal que se efetuou no trabalho compreendeu o período de março a julho de 2009, o que significou uma amostragem de cem exemplares. A seleção do corpus de pesquisa (jornais Pioneiro, Zero Hora, Correio do Povo e Folha de S. Paulo) se justifica na medida em que o primeiro deles tem circulação na região Nordeste da serra gaúcha; o segundo, Zero Hora, tem circulação estadual, mas como pertence ao mesmo grupo do jornal Pioneiro, optou-se por trabalhar, também, com o jornal Correio do Povo, igualmente de circulação estadual; e o último jornal selecionado, Folha de S. Paulo, integra a pesquisa em função de ter circulação nacional, estar sediado no centro do País e ser o jornal de maior circulação nacional. 


\section{De que violência fala a mídia?}

O jornal Pioneiro foi adquirido pelo grupo RBS em 1993, circula na região de Caxias do Sul, na serra gaúcha. Cobrindo as cidades mais importantes do referido território, tem uma penetração de $92 \%$ em seu mercado. Segundo dados do Instituto Verificador de Circulação (IVC), em fevereiro de 2010, a publicação média do jornal foi de 25.847 exemplares. Em março de 2007, o Correio do Povo passou a fazer parte do conglomerado de mídia controlado pelo grupo da Igreja Universal do Reino de Deus, do Bispo Edir Macedo, juntamente com outras empresas do grupo, a TV Guaíba e as rádios Guaíba AM e FM. De acordo com pesquisa do IVC, de novembro de 2006, o Correio do Povo é o segundo jornal gaúcho em tiragem e o oitavo brasileiro. O IVC informou que a publicação média do veículo, em fevereiro de 2010, foi de 154.070 exemplares. O jornal Zero Hora foi fundado em 4 de maio de 1964. De acordo com tabela do IVC, apresentou a média de 185.307 exemplares em fevereiro de 2010. A Folha de S. Paulo é o jornal de maior circulação do Brasil segundo dados do IVC, com uma tiragem de mais de um milhão de exemplares. Ao lado de O Estado de S. Paulo, O Globo e Jornal do Brasil, a Folha é um dos veículos impressos mais influentes. A média de publicação do jornal, apontada pelo IVC, foi de 287.873, em fevereiro de 2010.

\section{As dobras dos textos}

Na perspectiva do discurso, a grande discussão recai sobre o sujeito e sobre a dialética das relações que ele estabelece recorrendo a mecanismos e conceitos, como os de ideologia, de Estado, de liberdade e a todo um arcabouço teórico do qual (ele, sujeito) acaba por parecer alienado e ao qual figura como "assujeitado". Isso, em hipótese alguma, pode ser pensado como casual/acidental. Se, em um primeiro momento, o motor desse processo seria a necessidade de segurança e o próprio convívio, na etapa subsequente dá impulso a disputas pelo poder e à sua manutenção (BRANDÃo, s.d.) ${ }^{3}$.

Assim, talvez se possa pensar a possibilidade de o sujeito não estar irrevogavelmente preso à condição de sobrevivência/miséria/dependência/ignorância. O que acontece é o apagamento de sua capacidade perceptivo-cognitiva com

\footnotetext{
${ }^{3}$ Assujeitamento ideológico consiste, de acordo com o pensamento althusseriano, em fazer com que cada indivíduo (sem que ele tome consciência disso, mas, ao contrário, tenha a impressão de que é senhor de sua própria vontade) seja levado a ocupar seu lugar, a identificar-se ideologicamente com grupos ou classes de uma determinada formação social. É o mesmo que interpelação ideológica (Brandão, Helena H. Nagamini. Introdução à análise do discurso. 7. ed. Campinas: Unicamp, 1998).
}

uma espécie de "cortina de fumaça", tecida com subterfúgios, como o discurso midiático, e uma série de instituições que determinam comportamentos/reprimem reações, em nome de uma entidade que, até a contemporaneidade, encontrou concretude, mas que, na sociedade contemporânea, parece fadada a desmascarar quem, na verdade, detém e manipula o poder.

Em Pobreza, crime e trabalho, Deccache-Maia destacou:

\begin{abstract}
$\mathrm{O}$ que se pode fazer diante de experiências vividas e revividas quotidianamente? $\mathrm{O}$ resultado disto tem sido a absorção da experiência e uma postura de defesa diante dela. O olhar desconfiado decorre das inúmeras vivências de situações de violência onde é construído no imaginário social um "tipo padrão". Dito de outra forma, o direcionamento deste "olhar desconfiado" se volta para a imagem gravada nas cenas, fazendo com que todos os que possuem esse "tipo padrão" sejam enquadrados na situação detonadora desta tipificação (2010) ${ }^{4}$.
\end{abstract}

A autora em destaque enfatizou ainda: "Ser pobre e negro já seriam duas características suficientes para descrever o tipo e fazer com que muitos transeuntes mudassem seu trajeto para evitar o risco de ser protagonista de uma dessas cenas de violência" (ibidem). Por conseguinte, a presente pesquisa desenvolve-se justamente na direção de denunciar uma naturalização entre as noções de pobreza e violência e mesmo entre violência e juventude (pobre), alimentada pelo discurso midiático.

O trabalho mencionado (Deccache-Maia) selecionou 554 matérias, no período de 1989 a 1992, todas focadas na questão do trabalho infanto-juvenil. Ao abordar a criação do Estatuto da Criança e do Adolescente, promulgado em 6 de outubro de 1990, e a determinação da idade mínima de 14 anos de idade para o trabalho pela Constituição de 1988, a pesquisadora citada iniciou uma interessante discussão sobre a ideia de que, longe de uma atividade laboral, o jovem pobre está fadado à criminalidade. As matérias analisadas não referem à questão da educação. A noção de educação aparece, sempre, colada ao trabalho, que, sabe-se, é extremamente mal remunerado. Fala-se, então, em reprodução das condições de trabalho, assujeitamento dos indivíduos sociais e subserviência/servilismo a um modelo social/econômico desenhado.

Aqui se ressalta, também, a forte contribuição que os meios de comunicação oferecem no sentido de desfocar a atenção em relação às efetivas causas da situação precária desses atores sociais, enquanto fortalece, no imaginário

\footnotetext{
${ }^{4}$ Disponível em: <www.senac.br/BTS/232/boltec232b.htm>. ( s. p. s.d.). Acesso em: 4 de abril de 2010.
} 


\section{De que violência fala a mídia?}

social, um verdadeiro estereótipo ${ }^{5}$ de violência, usando como estandarte, na verdade, o "sintoma" descolando o episódio selecionado do contexto social em que ocorre.

\section{Segundo Deccache-Maia:}

Seria possível continuar elencando outros tantos testemunhos na mesma linha. A maioria do material jornalístico referente a esse assunto, nos quatro cantos do país, apresentou a mesma argumentação. A ocupação da população infanto-juvenil em situação de exclusão social, de preferência em experiências de formação para o trabalho é, pois, o objetivo maior de grupos de pessoas a instituições que promovem experiências voltadas para este fim. Secundariza-se, dessa forma, no discurso, o caráter educativo, sobrepujado pelo tom emergencial (2010).

Podem ser destacadas diversas matérias publicadas nos veículos selecionados, em que a questão da "juventude" é evidente, mesmo que inconsistente. São categorizados como jovens os sujeitos que vão da menoridade aos $29 \mathrm{e}$ 32 anos de idade ${ }^{6}$, por exemplo, como se vê na matéria "Dois homens acabaram presos (jovem nega tentativa de assalto") ${ }^{7}$. O jovem a que aludiu a matéria tem 32 anos de idade. Em outra matéria, a referência é a uma mulher, com 29 anos de idade, também categorizada como "jovem".

Uma mesma palavra assume sentidos opostos, conforme o discurso onde está inserida. Bakthin (1988: 32) afirmou que [ela] "é a arena privilegiada onde se desenvolve a luta de classes". Portanto, pode-se dizer que os diversos discursos materializam-se em "visões de mundo das diferentes classes sociais com seus interesses antagônicos: são as várias formações ideológicas correspondentes às várias formações discursivas" (BrandÃo, 1998: 52). Pêcheux

\footnotetext{
${ }^{5}$ Sempre que alguém é categorizado, rotulado ou tem seu papel definido - estereotipado - comportamentos, características e ações são esperados. Dentro de todo sistema cultural, esperase que vários grupos se comportem de maneira mais ou menos específica. Se eles falham em corresponder, uma variedade de reações pode ser antecipada - surpresa, raiva, desapontamento, temor ou mesmo desgosto. Se as expectativas foram respondidas de forma inconsciente, a reação é imprevisível, mas provavelmente será agressivamente negativa (KEY, Wilson Bryan. A era da manipulação. Lisboa: Scritta, 1990).

${ }^{6}$ De modo geral, uma percepção mais ou menos universal sobre a noção de juventude a "caracteriza por seu marcado caráter de limite", situada que está "no interior das margens móveis entre a dependência infantil e a autonomia da vida adulta" (LEVI \& Schmitт, 1996: 8, vol. 1).

7 Jornal Pioneiro, número 10.374, 18 de março de 2009, p. 16. Editoria de Segurança. A mesma edição registrou o assassinato de um estudante universitário em um motel. O título "Jovem foi assassinado em motel" chamou a atenção para a vítima, antes de focar o fato em si: o crime.
}

mostrou que "as palavras, expressões, proposições etc. mudam de sentido em referência a essas posições, isto é, em referência às formações ideológicas nas quais essas posições se inscrevem" (PÊCHEUX, 1988: 169). Parece importante destacar que a linguagem pode funcionar como centro de poder.

Ao se pensar a polifonia ${ }^{8}$ do discurso, ocorre uma indução para se falar em possibilidade de pontos de fuga. Assim, a engrenagem midiática desenvolve um esforço redobrado e normalmente competente no sentido de minimizar a capacidade reativa do sujeito, que acaba, em um processo recursivo, por realimentar o discurso que recebeu. Tem-se na mídia a ausência da crítica, da reflexão, da diversidade de pontos de vista; tem-se um discurso tautológico da violência por ela própria. Exemplo disso é a matéria especial, abrigada na cartola "Violência", cujo título é "Mortes disparam"9. O jornal publicou extensa lista onde arrolou nome da vítima, as circunstâncias do crime, motivação, situação e autor. A reportagem completa cobriu duas páginas e desenhou um cenário de violência exacerbada. Considere-se que a matéria apontou um crescimento de $30 \%$ no número de mortes por crimes (na verdade, o dado preciso apareceu depois, com menor destaque: $28,2 \%$ ), considerando o primeiro trimestre de 2009 em relação ao mesmo período de 2009. As tabelas, porém, mostram ocorrências de 12 municípios, sem mencionar, por exemplo, a relação entre o número de mortos e a população considerada, fato que causaria, com certeza, um impacto sensivelmente menor.

Além disso, a matéria apontou o aumento do contingente de policiais na região, o que deixa clara a questão da substituição da causa pelo sintoma, no tratamento do problema pela imprensa. O problema não está, portanto, na repressão, mas na prevenção, que significaria, por exemplo, investimento na educação e na cidadania como valor.

Normalmente, os jornais limitam-se a informar gênero, idade, condição de trabalho (empregado ou desempregado) no registro de ocorrências criminais. O desemprego estrutural não entra em questão, e, se o infrator/criminoso estiver empregado, a empresa onde trabalha não é mencio-

\footnotetext{
8 "A problemática da polifonia põe em causa a unicidade do sujeito falante [...] Esta foi introduzida por Bakthin nos seus trabaIhos sobre literatura para caracterizar obras, por exemplo, os romances de Dostoievski (BAKHTIN, 1970), nos quais várias vozes se exprimem sem que nenhuma seja dominante, mas a polifonia foi explorada pelos linguistas, em especial por Ducrot, para dar conta dos múltiplos casos em que aquele que produz materialmente o enunciado NÃO O TOMA A SEU CARGO, não se coloca como seu responsável (MaInguenEAU, Dominique. Os termoschave em análise do discurso. Lisboa: Gradiva, 1997).

${ }^{9}$ Jornal Pioneiro, número 10.387, 2 de abril de 2010, p. 14-15.
} 
nada. Desemprego e crime são relacionados de forma direta, sem tangenciar o modo como a sociedade está estruturada. Dessa forma, o veículo de comunicação impressa colabora para a exclusão/o preconceito, ao promover diferenças entre os membros de uma comunidade, acabando por estabelecer/criar estereótipos.

A hipérbole, de modo leigo definida como "exagero", deveria estar ausente de matérias noticiosas e mesmo reportagens, num jornalismo que se define pela objetividade e precisão. A premissa cai por terra, porém, no exemplo que segue: "Caxias do Sul em fúria"10. Expressões como "A violência está enraizada"; "E a culpa não é só dos criminosos" - impactantes e generalizadoras - são alarmistas e despertam no imaginário social um quadro de violência generalizada. Veja-se o trecho a seguir:

\begin{abstract}
Ela vem à tona em endereços conhecidos ou improváveis, contaminando famílias e corrompendo as relações. Um impulso que não respeita nenhuma instituição ou lei e que atende por um nome: fúria. A todo o momento, a cidade assiste a cenas de intolerância protagonizadas por homens, mulheres e adolescentes. Um sintoma que cresce entre as chamadas pessoas de bem que, ao contrário dos criminosos comuns, não teriam motivos para se envolver em atos violentos.
\end{abstract}

Além do exagero digno de ficção, a matéria estabeleceu uma divisão matemática: existem duas categorias, as pessoas "de bem" e a dos "criminosos", como se o caso tratasse de uma questão simplesmente (ou simploriamente?) genética. O texto fala em "epidemia", que não se restringe ao município-sede do jornal: "Esses sintomas não são percebidos apenas na maior cidade serrana, reforçando a teoria dos especialistas de que a região convive com uma epidemia". Em seguida, a matéria mencionou diversos episódios que, reunidos, dão ideia de verdadeira chacina, mas são registros ocorridos em todo o Estado do Rio Grande do Sul, e em diferentes períodos.

A reportagem referiu 786 homicídios em Caxias do Sul nos últimos dez anos. O número não é desprezível. Mesmo que se faça a média anual - 78, ele mantém força. Porém, se for considerada, por exemplo, a população global, sua força despenca significativamente. E se, na análise, forem categorizados em blocos diferentes homicídios dolosos e homicídios culposos, somente a título de exemplo, a estatura do número reduz-se ainda mais. A matéria não traçou um perfil dos crimes predominantes, mas também não delineou um perfil das mudanças sociais, econômicas e

10 Matéria publicada no jornal Pioneiro, de 21/23 de março de 2009 (ano 61, n. 10.377, p. 14, abrigada na cartola especial/ comportamento). políticas pelas quais passou a população referida, mas que, com certeza, são fatores importantes no comportamento do grupo social.

O jornal levantou a questão de desumanização dos sujeitos, sem, no entanto, mencionar/analisar o contexto, resultante de uma sociedade capitalista neoliberal que substitui a preocupação da solidariedade e da humanização pela competição e pelo consumo.

\section{A parcialidade se repete}

Está claro que ponto de partida aqui considerado para análise é o texto noticioso: estereótipo do texto jornalístico. Nele, foram encontradas, pretensamente, características apregoadas pela imprensa, como objetividade, neutralidade e clareza nas informações. Para cumprir esses objetivos, todo texto é submetido a um controle editorial, encarregado de padronizar a linguagem. Vale lembrar Traquina (2001), mais uma vez, quando este falou na "teoria do espelho", cuja "noção-chave [é a de que] o jornalista é um comunicador desinteressado, isto é um agente que não tem interesses específicos a defender e que o desviam da sua missão de informar, procurar a verdade, contar o que aconteceu, doa a quem doer". (p. 65, grifo do autor). Talvez seja importante relembrar a presença do copidesque na imprensa brasileira durante a vigência da ditadura militar que se iniciou em 1964, estendendo-se por duas décadas. Ele era o todo-poderoso da redação durante aquele período.

Os manuais de redação pregam que o profissional deve relatar os fatos de acordo com a realidade (verossimilhança), de forma clara, direta e objetiva, e afastar qualquer dúvida sobre a imparcialidade jornalística. No estudo desenvolvido, no entanto, observaram-se discursos caracterizados pela associação entre pobreza urbana e criminalidade violenta, para citar apenas um exemplo.

Uma breve análise comparativa estampa a questão que se pretende abordar. O jornal Pioneiro, de 31 de março/ 1o de abril de 2007, às páginas 16 e 17, na matéria "Fortuna suspeita", em que a Polícia e a Receita Federal prenderam quatro pessoas envolvidas com um megaesquema de sonegação e lavagem de dinheiro, não divulgou o nome dos presos, com a plausível justificativa de que a Polícia e a Receita Federal os mantêm em sigilo. Mas, na edição de 6 de abril, quando noticiou, à página 19, que o servente de pedreiro "supostamente envolvido" na morte da menina Gabrielle Cristina Eichholz, de um ano e meio, na Igreja Adventista do Sétimo Dia, de Joinville, Santa Catarina, reafirmava sua inocência, ignorou o código de ética e "divulgou" o nome do envolvido, mesmo que suspeito apenas.

No mesmo jornal, de 6 de abril, à página 13 (Segurança), encontra-se a matéria "Adolescente morto a facadas". 


\section{De que violência fala a mídia?}

Em nota relativamente breve, o jornal relatou o episódio, mas o interessante foi a forma redundante adotada para induzir a um cenário maior e predominantemente violento. Na abertura, uma cartola"11 - "Violência: 23ํassassinato deste ano". A mesma afirmação encerrou o texto no jornal: "Este foi o 23ㅇassassinato de 2007 em Caxias do Sul". A partir do olhar de Bauman, quando este afirmou que "escapar do medo é o melhor ponto de venda", podese fazer uma leitura interessante desse discurso e atribuir-Ihe uma intencionalidade (BAUMAN, 2004: 116). O autor asseverou que nada vende tanto quanto os dispositivos antimedo,

[...] e o sintoma mais evidente da passagem do poder do Estado para o mercado é a política de cortar impostos, uma política cuja linha mestra é o retorno ao mercado de fundos anteriormente carreados para os cofres do Estado, a fim de financiarem a segurança individual socialmente fornecida. Em outras palavras, a "comercialização do medo" - a transferência maciça do recurso chamado "medo" da esfera do poder político para a dos atores do mercado. Desse recurso foi o primeiro a ser "desregulamentado" e "privatizado". Cabe agora ao mercado de consumo lucrar com o medo desassistido em outros sentidos. E ele o faz - com prazer e habilidades cada vez maiores (BAUMAN, 2004: 116).

Não se pode simplesmente crer que o sujeito social seja apenas resultado da repressão/manipulação, mas, sim, construtor dela, na permanente disputa pelo poder. A tecnologia informacional, assim, não tem poder por si mesma. O que parece acontecer é que sujeito/grupos organizados, na disputa pelo poder, criam entidades às quais delegam legitimidade/autoridade de discurso, ou seja, a mídia se atualiza como algo independente e regulador do comportamento social, cada vez mais atenta às possibilidades de reação/fuga do sujeito.

Isso fica evidente quando se analisa, por exemplo, a matéria "Justiça - Acusado tenta trancar ação de custo de lavagem de dinheiro de $\mathrm{R} \$ 2,2$ bi" (cartola "Justiça", na editoria de Economia), na página 28 do jornal Zero Hora, de 7 de maio de 2009, quinta-feira, foi deslocada para a editoria de economia, quando seu conteúdo estava eminentemente relacionado à criminalidade. Entende-se tal distorção como verdadeiro ato de violência da mídia em relação à sociedade a que deveria servir. Essa postura traduz com clareza o título que se atribuiu à esta pesquisa. Esse tipo de violência impingido por determinados grupos sociais articulados com o poder, assim como a descontextualização de episódios relacionados à criminalidade, é o discurso

\footnotetext{
${ }^{11}$ Palavra, simples ou composta, na abertura de editoria/matéria, que identifica o assunto.
}

sobre violência do qual a mídia não fala ${ }^{12}$. O fato se repete, por exemplo, em matéria que relatou a apreensão de um arsenal de armas em poder de proprietários de terra envolvidos, também, em roubo de cavalos de raça.

Esse mesmo expediente está presente no jornal Zero Hora, de 11 de junho de 2009, página 21, editoria de polícia, "Susepe contrata 210 servidores".

O Governo do Estado, através da Superintendência dos Serviços Penitenciários (Susepe) e Secretaria da Segurança Pública (SSP), está contratando, emergencialmente, 210 servidores, sendo 26 advogados, 110 assistentes sociais e 74 psicólogos, para exercerem suas funções nas regiões penitenciárias da secretaria.

Publicada da forma como o foi, e na editoria de polícia, a matéria soma mais como alerta ao fantasma presente da violência do que para a qualificação da infraestrutura do estado na prevenção à criminalidade.

\section{Como evidenciou Caleiro:}

Nessa confusão acelerada, reflexiva e sempre aparentemente consensual o que é e o que não é violência passa a ser determinado por um aparato midiático que tem no

${ }^{12}$ STF nega liminar a ex-diretor da Bombril / Acusado de participar de um megaesquema de lavagem de dinheiro, entre outros crimes, o ex-diretor da Bombril Joamir Alves não obteve o pedido de liminar para trancamento da ação penal à qual responde, conforme solicitado por sua defesa ao Supremo Tribunal Federal.

A decisão do ministro do SPF, Joaquim Barbosa, foi publicada na última terça-feira. De acordo com a acusação, entre 1996 e 2001, a Bombril fez, junto com outras empresas uma operação de lavagem de dinheiro envolvendo $\mathrm{R} \$ 2,2$ bilhões. As investigações sobre o caso apontaram que o esquema terá envolvido a produção de documentos forjados e registro de falsas declarações ao Banco Central para ocultar a finalidade das transferências internacionais.

O Ministério Público Federal chegou a qualificar o caso como "a maior lavagem de dinheiro operada no Brasil, a partir de uma única empresa, agravada pela circunstância de haver se valido do nome prestigioso que possuía no mercado".

Executivo sustenta que não houve direito a ampla defesa / Por ter sido diretor financeiro e de relações com investidores e superintendente da Bombril nos anos 2000 e 2001, Alves responde ao processo. Nos autos, a defesa do executivo afirma que sua conduta criminosa não foi devidamente individualizada na denúncia, constituindo-se como genérica e não permitindo o direito a ampla defesa. Também afirma que ele não foi o responsável pelos atos apontados, figurando como denunciado apenas por pertencer ao contrato social da empresa.

Barbosa negou o pedido de liminar para trancar a ação penal, argumentando que a descrição minuciosa e individualizada da conduta de cada acusado não é necessária, bastando a denúncia permitir o direito de ampla defesa, o que teria sido assegurado. 


\section{De que violência fala a mídia?}

capital a base (estrutura físico-operacional), o meio (comercialização de espaços/tempo viabilizando a produção) e o fim (retorno em forma de audiência/público proporcionando o lucro). Cria-se, em decorrência, um quadro valorativo a partir de valores subjetivos, que camuflam a violência enquanto estrutura e espetacularizam as manifestações cotidianas de delinquência que dela decorrem (2003, s. p.).

Os jornais Zero Hora 191 (p. 23) e 269 (p. 21) deram o mesmo tratamento a duas matérias sobre roubo de cavalos. Na primeira delas, lê-se:

\begin{abstract}
Uma operação da Polícia Federal apreendeu, em Caçapava do Sul e Porto Alegre, 70 cavalos, seis malotes com documentos e um cofre. A suspeita é de que a criação de animais e a manutenção de um haras no interior do Estado fossem formas de lavagem de dinheiro usados por uma quadrilha especializada em fraudes em licitações, presa na terça-feira.
\end{abstract}

Setenta cavalos representam um investimento substancial e exigência de capital significativo. A notícia, no entanto, não entrou nesse aspecto. Tampouco mencionou qualquer suspeito, o que pode levar a pensar na influência e na pressão exercida sobre o veículo/repórter (TRAQUINA, 2001). O jornal não voltou a referir o assunto nas edições subsequentes. A matéria recebeu o mesmo tratamento editorial da que segue:

Policiais do 25 BPM de São Leopoldo prenderam dois jovens de 22 e 21 anos, e apreenderam uma adolescente de 13, na madrugada de ontem, roubando gado, na região. O trio foi flagrado ao conduzir duas vacas das raças holandesa e Jersey e uma novilha, pelas vielas do bairro Rio dos Sinos.

O texto não estabelece diferença entre um sofisticado esquema de lavagem de dinheiro, que envolve um haras, e o roubo de duas vacas, levado a efeito por três adolescentes, fato que passa despercebido ao leitor apressado, que poderá, inclusive, deixar-se impressionar mais pela idade do mais infrator dos jovens, 13 anos, do que pela sofisticação do esquema de lavagem.

\section{Considerações finais}

Ao final desta reflexão, inferiu-se que é perigoso concluir, na medida em que concluir é uma atitude de fechamento. A intenção deste artigo não foi encerrar, mas abrir, descortinar, alertar leitores e futuros leitores. Não há escrita inocente, como não há leitura inocente. $\mathrm{Na}$ intenção da comunicação, o que se coloca é a permanente disputa de poder. O discurso é o cenário onde são representados os mais diversos papéis, a arena onde atores exibem seu talento, na disputa pelo melhor lugar.

Em tempos de rede, nada está isolado, unitário, solo. Forças em relação se atualizam permanentemente, e não se pode esquecer que elas passam pelo discurso, na qual, já disse Lacan (2006), o homem se constitui.

A disposição aqui manifestada é a de contribuir para a formação de um leitor menos ingênuo, o que significa aberto à possibilidade ampliada de uma multiplicidade de estratégias de enunciação e construir/discursivar a realidade não a partir do medo, mas da pluralidade e diversidade, como incentivaram Lago \& Benetti (2008).

Entende-se, assim, que a violência que a mídia cala está presente em no cotidiano das pessoas em geral, de forma dissimulada e ininterrupta, basta relembrar as análises feitas ao longo do artigo.

O artigo registra o início da análise do discurso e de conteúdo dos jornais selecionados, embora sinalize positivamente para a hipótese de que os jornais Correio do Povo, Pioneiro, Zero Hora e Folha de S. Paulo tratam das questões de violência de forma a criar um estereótipo que acaba por encobrir os verdadeiros fatores desencadeadores do fenômeno, relacionados a questões de infraestrutura, contexto social, modelo político/econômico. A análise mostra, de forma clara, também, dois aspectos não levantados inicialmente na pesquisa: a propensão de os jornais "colarem" ao perfil dos criminosos o conceito de juventude e a tendência de tais publicações dissimularem eventos criminosos, deslocando-os da editoria de polícia. 


\section{De que violência fala a mídia?}

\section{Referências}

Althusser, Louis. Ideologia e aparelhos ideológicos do Estado. Porto: Presença, 1974.

Aparelhos ideológicos do Estado. São Paulo: Graal, 2003.

BAKTHIN, Mikhail. Marxismo e filosofia da linguagem: problemas fundamentais do método sociológico na ciência da linguagem. 9. ed. São Paulo: Hucitec, 1988.

BaUman, Zigmunt. Europa. Rio de Janeiro: Zahar, 2004.

Brandão, Maria Helena. Introdução à análise do discurso. 7. ed. Campinas: Unicamp, 1998.

Caleiro, Mauricio de Medeiros. A Folha de S. Paulo e a infância marginalizada. Disponível em: <http://www. bocc.uff.br/pag/caleiro-mauricio-folha-sao-paulo-infanciamarginalizada.pdf>. Acesso em: 5 de abril de 2010.

Deccache-MaiA, Eline. Pobreza, crime e trabalho. Boletim Técnico do Senac, v. 23, p. 12-21, Rio de Janeiro, 1997. Disponível em: <http://www.egov.ufsc.br/portal/sites/ default/files/anexos/10435-10435-1-PB.htm>. Acesso em: 4 de abril de 2010 .

FonSECA, Virgínia. O jornalismo na era da sociedade em rede: máxima informação e ilusão da realidade. In: HohlFELdT, Antônio \& BARBosa, Marialva. Jornalismo no século XXI: a cidadania. Porto Alegre: Mercado Aberto, 2002.

Foucault, Michel. Vigiar e punir. Petrópolis: Vozes, 1987. 2002.
KEY, Wilson Bryan. A era da manipulação. Lisboa: Scritta, 1990.

LaCAN, Jacques. Meu ensino. Rio de Janeiro: Zahar, 2006 (Coleção Campo Freudiano no Brasil).

LeVI, Giovanni \& SchmitT, Jean-Claude. A história dos jovens: da Antiguidade à era moderna. Vol. 1. São Paulo: Companhia das Letras, 1996.

Maingueneau, Dominique. Os termos-chave da análise do discurso. Lisboa: Gradativa, 1997.

MARTINO, Luís Mauro Sá. Teoria da comunicação: ideias, conceitos e métodos. Petrópolis: Vozes, 2009.

Morin, Edgar. 2005. O método 6: a ética. Porto Alegre: Sulina, 2005.

PÊCHEux, Michel. Semântica e discurso: uma crítica à afirmação do óbvio Campinas: Unicamp, 1988.

Srour, Robert. Poder, cultura e ética nas organizações. 9. ed. Rio de Janeiro: Campus, 1998.

Traquina, Nelson. $O$ estudo do jornalismo no século $X X$. São Leopoldo: Unisinos, 2001.

\section{Corpus da pesquisa}

Jornal Pioneiro, edições de 6 de abril de 2007, 18 de março de 2009, 21 de março de 2009, 23 de março de 2009, 31 de março de 2009 e 2 de abril de 2009.

Jornal Zero Hora, edições de 6 de abril de 2007, 7 de maio de 2009, 12 de maio de 2009 e 11 de junho de 2009. 